\title{
Papers
}

\section{Post-combat syndromes from the Boer war to the Gulf war: a cluster analysis of their nature and attribution}

\author{
Edgar Jones, Robert Hodgins-Vermaas, Helen McCartney, Brian Everitt, Charlotte Beech, \\ Denise Poynter, Ian Palmer, Kenneth Hyams, Simon Wessely
}

\begin{abstract}
Objectives To discover whether post-combat syndromes have existed after modern wars and what relation they bear to each other.

Design Review of medical and military records of servicemen and cluster analysis of symptoms. Data sources Records for 1856 veterans randomly selected from war pension files awarded from 1872 and from the Medical Assessment Programme for Gulf war veterans.

Main outcome measures Characteristic patterns of symptom clusters and their relation to dependent variables including war, diagnosis, predisposing physical illness, and exposure to combat; and servicemen's changing attributions for post-combat disorders.

Results Three varieties of post-combat disorder were identified-a debility syndrome (associated with the 19th and early 20th centuries), somatic syndrome (related primarily to the first world war), and a neuropsychiatric syndrome (associated with the second world war and the Gulf conflict). The era in which the war occurred was overwhelmingly the best predictor of cluster membership.

Conclusions All modern wars have been associated with a syndrome characterised by unexplained medical symptoms. The form that these assume, the terms used to describe them, and the explanations offered by servicemen and doctors seem to be influenced by advances in medical science, changes in the nature of warfare, and underlying cultural forces.
\end{abstract}

\section{Introduction}

It is now clear that service in the Gulf war is associated with an increased rate of reported symptoms and worsening subjective health, ${ }^{1}$ even if most research has not confirmed the existence of a specific new syndrome..$^{2-4}$ The question we address is whether this phenomenon is unique to the Gulf war or has been seen after previous conflicts. In a review based on secondary sources Hyams et al surveyed war syndromes from the US civil war to the Gulf conflict and identified two features that suggested a common relation-the similarity of symptoms and a high frequency of reported diarrhoea and other infectious diseases preceding onset. $^{5}$
This study was designed to discover more about the essential characteristics of post-combat syndromes from 1854 . When assessed by their symptomatology are they the same, distinct, or akin to varieties within a single species? Did cultural forces and technological advance in warfare affect the overall form of these disorders, the descriptive terms, and the explanations adopted by veterans and doctors?

\section{Subjects and methods}

\section{Data sources}

We used war pension files as the primary data source because they contained detailed medical and military reports. The assessment procedure for soldiers (regular boards composed of two doctors) did not change greatly over the study period, though the criteria were revised. After 1916, awards were no longer based on a veteran's ability to earn a living wage but were granted according to a standardised schedule of injury in which, for example, the loss of two or more limbs entitled a man to $100 \%$. Medical notes were in most cases detailed and covered servicemen's histories from enlistment until death, and death certificates were often included. Pensioners were required to attend regular medical boards to assess their disability, and specialist opinions were sought. As a result, symptoms were recorded throughout an individual's military service and after discharge. The long term nature of the notes allowed us to exclude cases if a serviceman was found to be suffering from an organic disorder or a major mental illness. We did not include prisoners of war because of the psychological stress they experienced and the nutritional deficits that many encountered. The investigation was restricted to members of the British army.

From six conflicts we identified 10 post-combat syndromes that typified the conflicts, and we included 1856 representative subjects in our study (table 1). (For a full description of our methods, see the appendix.)

Boer war-We surveyed the entire collection of 6276 files from the Royal Hospital, Chelsea, by diagnosis. We took a random sample of 200 cases of disordered action of the heart (DAH) or valvular disease of the heart where subsequent reports and death certificates indicated a functional disorder, together with 200 cases of rheumatism (in the absence of organic signs such as
Department of
Psychological
Medicine, Guy's,
King's, and
St Thomas's School
of Medicine,
London SE5 8AZ
Edgar Jones 
Table 1 War syndromes identified from war pensions for 1856 British servicemen

\begin{tabular}{lc} 
Conflict and syndrome & No of cases \\
\hline Victorian campaigns (1854-c1895) & 19 \\
\hline Palpitation & 9 \\
\hline Debility & 200 \\
\hline Boer war (1899-1902) & 200 \\
\hline DAH & \\
\hline Rheumatism & 200 \\
\hline First world war (1914-18) & 200 \\
\hline DAH & 167 \\
\hline Neurasthenia & 24 \\
\hline Gassed & 49 \\
\hline Nurses: & 67 \\
\hline DAH & 200 \\
\hline Neurasthenia & 100 \\
\hline Second world war (1939-45) & 1 \\
\hline Effort syndrome & 15 \\
\hline Psychoneurosis & 5 \\
\hline Dyspepsia & 400 \\
\hline Malayan (1948-60) and Korean (1951-53) conflicts \\
\hline Effort syndrome & \\
\hline Psychoneurosis & \\
\hline Dyspepsia & \\
\hline Gulf war (1991) & \\
\hline Gulf related illness & \\
\hline DAH & \\
\hline
\end{tabular}

$\mathrm{DAH}=$ disordered action of the heart.

inflammation and joint swelling). Both disorders were a major cause of invalidity from the forces. Contemporaries believed that DAH was caused by lengthy marching in equipment, which constricted blood flow to and from the heart, while rheumatism was considered a product of fever and exposure to wet conditions. ${ }^{6}$

First world war-Staff of the War Pensions Agency selected every 50th file from a total of 1137800 to generate a sample of 22756 , and from these we chose 200 cases of shell shock, or neurasthenia as it was reclassified in 1917, and 200 cases of DAH using a random number generator. We also selected 167 servicemen who had been gassed without permanent organic injury and every nurse who had been awarded a pension for DAH or neurasthenia.

Second world war-We chose three diagnostic groups-effort syndrome (for comparison with the Boer war and first world war samples of DAH), psychoneurosis (for comparison with neurasthenia), and non-ulcer dyspepsia. The focus of health concerns

\section{Commonest symptoms in 1856 British servicemen with post-combat syndromes in order of frequency}

1 Difficulty completing tasks

2 Fatigue or lethargy

3 Shortness of breath

4 Persistent anxiety

5 Weakness

6 Rapid or irregular heartbeat

7 Headaches

8 Difficulty sleeping

9 Tremor, shaking, or trembling

10 Dizziness or giddiness

11 Depression or low mood

12 Pains in joints

13 Changes in weight
14 Irritability

15 Forgetfulness or memory loss

16 Back pain

17 Poor concentration

18 Stomach cramps or abdominal pain

19 Heavy or persistent sweating

20 Changes in personality

21 Nightmares

22 Jumpiness or easily startled

23 Tenderness or soreness

24 Persistent cough

25 Diarrhoea in Britain switched from the heart in the first world war to the stomach in the second. ${ }^{7}$ To reflect this important change in medical priorities, we randomly selected 100 cases of non-ulcer dyspepsia from war pension files. We also randomly selected 200 cases of psychoneurosis, but we included all cases of effort syndrome because relatively few pensions were awarded for this disorder.

Malayan and Korean conflicts-We encountered considerable problems in finding awards for psychoneurosis, effort syndrome, and dyspepsia from Korea and Malaya partly because troops deployed there represented only a small proportion of the UK armed forces. We included all cases.

Gulf war-Although pensions have been granted to veterans of the Gulf war, we were not granted permission to consult these files. Nevertheless, it was important to study a group who felt that their health was damaged by military service. The Ministry of Defence granted us access to anonymised case records from the Gulf Veterans' Medical Assessment Programme. From their database of 2162 army personnel, we randomly selected 400 Gulf veterans.

\section{Data collection}

To collect data in a standardised manner across different conflicts and disorders, we designed a form to record the following information.

- Servicemen's biographical details-dates of birth and death, cause of death, education, family history, occupation before and after military service, medical history

- Pension details

- Military record-nature of recruitment, unit, rank, date of enlistment, dates of discharge and service abroad, time in combat, and traumatic exposures

- 94 symptoms in the following groups-fatigue; cognition; cardiovascular and respiratory; gastrointestinal; genitourinary; central nervous system; locomotor system; eye; ear, nose, and throat; skin; psychological state; sleep problems; weight changes; and self inflicted wounds

- Results of medical investigations

- Servicemen's explanations for their symptoms and comments of examining physicians

- Military conduct with a summary of offences.

\section{Statistical analysis}

The form consisted of 94 possible symptoms to avoid missing common examples. But, because of computational problems and the inevitable overlap in the information provided by the large number of symptoms, these were reduced to the 25 most common (box).

The resulting dataset with 1856 individuals described by 25 variable values was then subjected to cluster analysis. Because of the large number of observations, we used a k-means algorithm to cluster the data, since more sophisticated clustering techniques cannot cope easily with so large a dataset. For a given number of groups, this method seeks to partition the data so as to minimise the pooled, within-cluster variance. $^{8}$ To determine the most appropriate number of groups, we used the gap statistic. ${ }^{9}$ This is a computationally intensive approach that builds a null distribution for the test statistic by repeated clustering of the data generated so as not to have any cluster structure. 


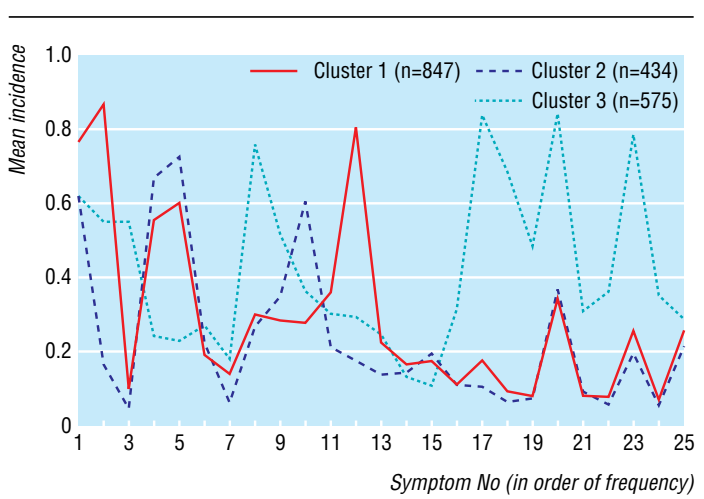

Mean incidence of 25 commonest symptoms in 1856 British servicemen with post-combat syndromes

\section{Results}

Use of the gap statistic resulted in the selection of three clusters of post-combat syndromes (see figure), which can be characterised as

Cluster 1-a debility syndrome but without psychological or cognitive symptoms

Cluster 2-a somatic syndrome focused on the heart

Cluster 3-a neuropsychiatric syndrome with a range of associated somatic symptoms.

Cluster 1 ( $n=847)$-Fatigue, difficulty completing tasks, shortness of breath, and weakness were prominent symptoms. Rapid heartbeat, tremor, headaches, dizziness, pains in joints, difficulty sleeping, changes in weight, and anxiety were moderately represented. Psychological symptoms such as depression, memory impairment, irritability, and poor concentration were notably absent. This clustering is indicative of a debility syndrome with associated physical signs. Cases were not drawn from any particular conflict (table 2), though $74 \%$ of subjects in the group came from wars fought before 1918.

Cluster $2(n=434)$-Rapid heartbeat, shortness of breath, fatigue and dizziness were prominent. Difficulty completing tasks, headaches, tremor, and anxiety were moderately represented. This symptom cluster is indicative of a functional cardiac syndrome, though the group represents only $39 \%$ of all cases of DAH and $44 \%$ of cases of effort syndrome. This reflects the degree of overlap in the three clusters and the fact that servicemen diagnosed with functional heart disorders had symptoms related to other areas of the body. Servicemen from the first world war, a conflict dominated by functional cardiac disorders, comprised $49 \%$ of the group, whereas the second world war and Gulf war contributed relatively few servicemen (19\% and $9 \%$ respectively) (table 2).

Cluster 3 ( $n=575$-Fatigue, headaches, depression, anxiety, and difficulty sleeping were prominent. Moderately represented were difficulty completing tasks, forgetfulness, rapid heartbeat, shortness of breath, tremor, dizziness, weakness, pains in joints, back pain, sweating, irritability, poor concentration, jumpiness, changes in personality, nightmares, and weight change. Although this cluster includes somatic symptoms, it is characterised by a range of psychological symptoms. Over half of the examples of neurasthenia (52\%), psychoneurosis (84\%), and Gulf war related illness (54\%) fell into this group.

\section{Predicting cluster membership}

To assess how much a particular factor explained the differences between these three groups, we conducted a logistic regression analysis using categorical variables. Cluster membership was the response variable, while conflict, sex, rank, nature of recruitment, military conduct, unit, predisposing physical illness, and attribution of symptoms were the explanatory variables. Variations between the individual wars (which were closely correlated to diagnostic terms) proved to be the best single predictor of cluster membership (table 3). Physical illness preceding onset of war syndrome, military conduct, and exposure to combat also had a mild predictive effect. The remaining variables, though significantly associated with cluster membership in themselves, gave no independent increase in prediction of membership over the four variables mentioned above.

\section{Predicting cluster membership by war}

The debility syndrome was largely drawn from veterans of the Victorian campaigns, the Boer war, and the first world war (table 2). The somatic syndrome represented the first world war with subsidiary elements drawn from the Boer war and the second world war. The neuropsychiatric cluster was predominantly composed of second world war and Gulf war servicemen. This suggests that there is an important temporal element running through these post-combat syndromes.

Predicting cluster membership by contemporary diagnosis

Because diagnosis tends to follow changes in medical knowledge and cultural developments, the temporal pattern identified in the analysis by war was also apparent from this variable (table 4). The debility syndrome, shown to be associated with the late 19th and early 20th centuries, also reflected the diagnoses of that period, notably DAH (disordered action of the heart) and rheu-

Table 2 Distribution of syndrome clusters in 1856 British servicemen with post-combat syndromes by conflict. (Values are numbers (percentages) of cases)

\begin{tabular}{lccc} 
& \multicolumn{3}{c}{ Post-combat syndrome cluster } \\
\cline { 2 - 4 } Conflict & $\begin{array}{c}\text { Debility } \\
\text { syndrome }\end{array}$ & $\begin{array}{c}\text { Somatic } \\
\text { syndrome }\end{array}$ & $\begin{array}{c}\text { Neuropsychiatric } \\
\text { syndrome }\end{array}$ \\
\hline Victorian campaigns $(\mathrm{n}=28)$ & $23(82)$ & $4(14)$ & $1(4)$ \\
\hline Boer war $(\mathrm{n}=400)$ & $308(77)$ & $91(23)$ & $1(0.3)$ \\
\hline First world war $(\mathrm{n}=640)$ & $292(46)$ & $213(33)$ & $135(21)$ \\
\hline Second world war $(\mathrm{n}=367)$ & $76(21)$ & $83(23)$ & $208(57)$ \\
\hline Malayan and Korea conflicts $(\mathrm{n}=21)$ & $2(10)$ & $5(24)$ & $14(67)$ \\
\hline Gulf war $(\mathrm{n}=400)$ & $146(37)$ & $38(10)$ & $216(54)$ \\
\hline Total & 847 & 434 & 575
\end{tabular}

Difference between clusters: $\chi^{2}=523, \mathrm{df}=10, \mathrm{P}<0.001$

Table 3 Summary of stepwise logistic regression analysis of membership of post-combat syndrome clusters in 1856 British servicemen by explanatory variables

\begin{tabular}{lrrrrrrr} 
& \multicolumn{2}{c}{$\begin{array}{c}\text { Improved prediction } \\
\text { of membership }\end{array}$} & & \multicolumn{3}{c}{ Goodness of fit } \\
\cline { 2 - 3 } \cline { 7 - 8 } Explanatory variable & \multicolumn{2}{c}{$\chi^{2}$} & P value & & $\begin{array}{c}\text { Degrees of } \\
\text { freedom }\end{array}$ & $\chi^{2}$ & P value \\
\hline None & 449.29 & $<0.001$ & & 672 & 750.57 & 0.019 \\
\hline Conflict & 9.91 & 0.007 & & 670 & 740.66 & 0.030 \\
\hline Physical illness & 17.04 & 0.009 & & 664 & 723.63 & 0.054 \\
\hline Military conduct & 5.01 & 0.080 & & 662 & 718.57 & 0.063 \\
\hline Exposure to combat & & & & & &
\end{tabular}


Table 4 Distribution of syndrome clusters in 1856 British servicemen with post-combat syndromes by contemporary diagnosis. (Values are numbers (percentages) of cases)

\begin{tabular}{lccc} 
& \multicolumn{3}{c}{ Post-combat syndrome cluster } \\
\cline { 2 - 4 } Diagnosis & $\begin{array}{c}\text { Debility } \\
\text { syndrome }\end{array}$ & $\begin{array}{c}\text { Somatic } \\
\text { syndrome }\end{array}$ & $\begin{array}{c}\text { Neuropsychiatric } \\
\text { syndrome }\end{array}$ \\
\hline Palpitation $(n=19)$ & $15(79)$ & $4(21)$ & 0 \\
\hline Debility $(n=9)$ & $8(89)$ & 0 & $1(11)$ \\
\hline DAH $(n=424)$ & $255(60)$ & $166(39)$ & $3(1)$ \\
\hline Rheumatism $(n=200)$ & $173(87)$ & $26(13)$ & $1(1)$ \\
\hline Neurasthenia $(n=249)$ & $86(35)$ & $33(13)$ & $230(52)$ \\
\hline Gassed $(n=167)$ & $86(51)$ & $79(47)$ & $181(84)$ \\
\hline Psychoneurosis $(n=215)$ & $17(8)$ & $17(8)$ & $15(22)$ \\
\hline Effort syndrome $(n=68)$ & $23(34)$ & $30(44)$ & $26(25)$ \\
\hline Dyspepsia $(n=105)$ & $38(36)$ & $41(39)$ & $216(54)$ \\
\hline Gulf related illness $(n=400)$ & $146(37)$ & $38(10)$ & 575
\end{tabular}

DAH=disordered action of the heart.

Difference between clusters: $\chi^{2}=796, \mathrm{df}=16, \mathrm{P}<0.001$.

matism. In addition, contemporary labels bear some relation to the three groups, though the matching is not exact. The neuropsychiatric cluster, for example, has $52 \%$ of servicemen with neurasthenia, while $87 \%$ of rheumatism cases are in the debility cluster.

Predicting cluster membership by servicemen's attributions of symptoms

Servicemen's explanations for these post-combat syndromes were culturally conditioned and varied across the century tied to prevailing health beliefs and concerns (table 5). Boer war servicemen diagnosed with DAH generally believed it to be the result of either physical illness $(26 \%)$ or of physical exertion (25\%). A different pattern emerged in the first world war, with physical exertion accounting for $45 \%$ of the DAH sample and $43 \%$ of the neurasthenia group. However, a substantial number of the latter (34\%) attributed their symptoms to the psychological stress of military service. They had, perhaps, been educated by psychologically minded physicians and the gradual incursion of psychiatric texts into medical and general literature.

The second world war saw this process continue, and $41 \%$ of the servicemen with psychoneurosis attributed their symptoms to psychological stress arising from military service, and a further $5 \%$ attributed their symptoms to stresses related to their domestic situation. By contrast, $44 \%$ of the dyspepsia population ascribed their symptoms to the physical exertions of active service, as did $37 \%$ of those with effort syndrome. Only $9 \%$ of the Gulf war sample believed that stress had a causal role, whereas 34\% thought that their condition was the result of toxic exposure.

Contemporary attributions made by servicemen broadly correlated with the symptom characteristics of the three groups. In the debility cluster, $61 \%$ believed that their illness was related to a physical illness, physical injury or strain, climate, or toxic exposure. By comparison, $143(64 \%)$ of the 224 who believed the psychological stress of military service was the cause of their illness came from the neuropsychiatric cluster. Equally, only $23(12 \%)$ of the 186 who believed that they were suffering from a physical illness were found in this group.

\section{Discussion}

Based on symptomatology, our study identified three types of post-combat syndrome. We found significant differences in the expression of symptoms between the three groups, implying that there is no single presentation common to all modern wars. Variations seem to be determined by the nature of combat, contemporary

Table 5 Attributions of 1856 servicemen for their post-combat syndromes by contemporary diagnosis. (Values are numbers (percentages) of cases)

\begin{tabular}{|c|c|c|c|c|c|c|c|}
\hline \multirow[b]{2}{*}{ Diagnosis } & \multirow{2}{*}{$\begin{array}{l}\text { Physical } \\
\text { illness }\end{array}$} & \multirow{2}{*}{$\begin{array}{c}\text { Injury or } \\
\text { physical strain }\end{array}$} & \multirow{2}{*}{$\begin{array}{l}\text { Climate and } \\
\text { environment }\end{array}$} & \multirow{2}{*}{$\begin{array}{c}\text { Toxic } \\
\text { exposure }\end{array}$} & \multicolumn{2}{|c|}{ Psychological stress } & \multirow{2}{*}{$\begin{array}{c}\text { Not } \\
\text { reported }\end{array}$} \\
\hline & & & & & In military service & Domestic & \\
\hline \multicolumn{8}{|l|}{ Victorian campaigns } \\
\hline Palpitation $(n=19)$ & $5(26)$ & $4(21)$ & $2(11)$ & 0 & 0 & 0 & $8(42)$ \\
\hline Debility $(n=9)$ & 0 & $2(22)$ & $3(33)$ & 0 & 0 & 0 & $4(44)$ \\
\hline \multicolumn{8}{|l|}{ Boer war } \\
\hline DAH $(n=200)$ & $51(26)$ & $49(25)$ & $22(11)$ & 0 & $2(1)$ & 0 & $76(38)$ \\
\hline Rheumatism $(\mathrm{n}=200)$ & $35(18)$ & $30(15)$ & $74(37)$ & 0 & $2(1)$ & 0 & $59(30)$ \\
\hline \multicolumn{8}{|l|}{ First world war } \\
\hline DAH $(n=200)$ & $35(18)$ & $90(45)$ & $12(6)$ & $3(2)$ & $8(4)$ & 0 & $52(26)$ \\
\hline Neurasthenia $(\mathrm{n}=200)$ & $11(6)$ & $85(43)$ & $4(2)$ & $3(2)$ & $68(34)$ & $1(0.5)$ & $28(14)$ \\
\hline Gassed $(n=167)$ & $1(1)$ & $12(7)$ & 0 & $141(84)$ & $2(1)$ & 0 & $11(7)$ \\
\hline \multicolumn{8}{|l|}{ Nurses: } \\
\hline DAH $(n=24)$ & $9(38)$ & $8(33)$ & $2(8)$ & 0 & 0 & 0 & $5(21)$ \\
\hline Neurasthenia $(n=49)$ & $10(20)$ & $20(41)$ & $3(6)$ & 0 & $6(12)$ & $2(4)$ & $8(16)$ \\
\hline \multicolumn{8}{|l|}{ Second world war } \\
\hline Effort syndrome $(n=67)$ & $5(7)$ & $25(37)$ & $5(7)$ & $1(1)$ & $14(21)$ & $6(9)$ & $11(16)$ \\
\hline Psychoneurosis $(n=200)$ & $9(5)$ & $65(33)$ & $7(4)$ & $1(1)$ & $82(41)$ & $10(5)$ & $26(13)$ \\
\hline Dyspepsia $(n=100)$ & $12(12)$ & $44(44)$ & $10(10)$ & 0 & $5(5)$ & 0 & $29(29)$ \\
\hline \multicolumn{8}{|l|}{ Malayan and Korean conflicts } \\
\hline Psychoneurosis $(n=15)$ & $2(13)$ & $3(20)$ & $1(7)$ & 0 & $2(13)$ & $5(33)$ & $2(13)$ \\
\hline Dyspepsia $(\mathrm{n}=5)$ & 0 & $3(60)$ & 0 & 0 & 0 & $1(20)$ & $1(20)$ \\
\hline Effort syndrome $(n=1)$ & 0 & $1(100)$ & 0 & 0 & 0 & 0 & 0 \\
\hline \multicolumn{8}{|l|}{ Gulf war } \\
\hline Gulf related illness $(n=400)$ & $1(0.3)$ & $9(2)$ & 0 & $137(34)$ & $33(8)$ & $2(1)$ & $218(55)$ \\
\hline Total & 186 & 450 & 145 & 286 & 224 & 27 & 538 \\
\hline
\end{tabular}

$\mathrm{DAH}=$ disordered action of the heart. 
medical knowledge, and important health beliefs and fears. Symptoms, diagnostic labels, and culture are not independent but linked in a dynamic relation. ${ }^{10}$ The term shell shock, for example, tied to the first world war, expressed the experience of trench warfare and its features (contractures, tremor, loss of speech) and conveyed something of the heightened stress that men endured. ${ }^{11} 12$

\section{Implications for Gulf war syndrome}

In terms of symptoms, illness related to the Gulf war does not stand apart from the other conflicts. Although most cases fell into the neuropsychiatric cluster, Gulf war veterans are found in all three groups. Hence, not all servicemen engaged in the same conflict can be categorised in the same way, though we did find underlying trends.

Gulf war syndrome has often been attributed to environmental hazards such as depleted uranium, pesticides, and the side effects of vaccinations. However, it may be inferred that the three syndromes are unrelated to any particular exposure as they occurred during several wars, albeit with different frequencies. An analysis of death certificates also showed that veterans with post-combat syndromes did not develop a particular organic illness or have increased mortality. ${ }^{13} 14$

\section{Reasons for apparent changes in post-combat syndromes}

Our findings are based on symptoms extracted from historical medical records subject to contemporary clinical perspectives. Both doctors and patients were probably more alert to symptoms that related to current health issues. In the first world war, when functional heart disorders accounted for over 15000 admissions in 1915 and the causes of DAH were still being investigated, ${ }^{15}$ cardiac symptoms were given prominence. By proposing the underlying psychological foundation of effort syndrome, Paul Wood and Maxwell Jones at Mill Hill plausibly prevented a further flood of cases during the second world war. During this conflict, when the epidemic of duodenal ulcers was almost at its peak, ${ }^{16}{ }^{17}$ gastrointestinal symptoms also became a focus for attention. Discharges from the British army reflected these trends in medical understanding. ${ }^{18}$ Although the prominence given to symptoms may have been influenced by prevailing diagnostic paradigms, this bias was mitigated by the fact that servicemen were examined over several decades and by different doctors, sometimes with specialist input.

Shorter has argued that the nature of medically unexplained syndromes has itself changed with a shift from apparently neurological symptoms such as paralyses, tremors, and fits to more ill defined and subjective symptoms such as fatigue, pain, and depression. ${ }^{19}$ The apparent reversal of the trend towards greater psychological attribution during the Gulf war may reflect the unique biohazards of that conflict or a counter reaction to the increased awareness of post-traumatic stress disorder from 1980. Although our data are consistent with these cultural shifts, we propose that what has changed is not the symptoms themselves but the way in which they have been reported by veterans and interpreted by doctors. ${ }^{20}$

\section{What is already known on this topic}

Service in the Gulf war is associated with an increased rate of reported symptoms and worsening subjective health

Post-combat syndromes have been described after most modern conflicts from the US civil war onwards

\section{What this study adds}

There seems to be no single post-combat syndrome but a number of variations on a theme

The ever changing form of post-combat syndromes seems to be related to advances in medical understanding, the developing nature of warfare, and cultural undercurrents

Because reported symptoms are subject to bias and changing emphasis related to advances in medical science or the discovery of new diseases, the characterisation of individual syndromes has to be treated with caution

Attributions by servicemen are generally consistent with symptom characteristics, though there seems to be a growing reluctance to consider the stress of military service as a cause

\section{Conclusions}

Post-combat syndromes have arisen after all major wars over the past century, and we can predict that they will continue to appear after future conflicts. What cannot be accurately forecast is their form, as they are moulded by the changing nature of health fears and warfare. Because war syndromes have been recognised as pensionable disorders and proved difficult to treat, they have cost governments considerable sums in financial assistance. In order to introduce preventive measures and devise effective clinical interventions, it is necessary to understand their characteristics. If each new post-combat syndrome is not interpreted as a unique or novel illness but as part of an understandable pattern of normal responses to the physical and psychological stress of war, then it may be managed in a more effective manner.

Specialist advice was sought in cardiology from Drs Stephen Holmberg and Iqbal Malik, in gastroenterology from Dr Ian Forgacs and Sir Christopher Booth, in radiology from Drs Michele Marshall, Erica Denton, and C N O'N Digges, and in medicine from Professor Harry Lee and Dr Roger Gabriel. The Department of Social Security provided access to the war pensions archive, and we thank Dr Elizabeth Braidwood, Jenny Robb, and Paul Griffiths. The Army Historical Branch helped with military sources.

Contributors: IP, KH, and SW designed the initial study, were grant holders, and contributed to the manuscript. EJ revised the study design, coordinated the study, collected data, and prepared the manuscript. RH-V, HMcC, CB, and DP collected data and contributed to the manuscript. BE performed the statistical analysis. EJ is guarantor for the study.

Funding: The study was funded by a grant from the US Army Medical Research and Materiel Command under grant DAMD17-98-1-8009. EJ was supported by a grant from the US Department of Defense.

Competing interests: None declared, except funding for EJ. 


\section{Appendix: notes on sources}

\section{Boer war}

All the surviving pension files for Boer war veterans, formerly administered by the Royal Hospital, Chelsea, are held at the Public Record Office (PIN71). An analysis of mortality and serial numbers showed that these are not a complete holding. They represent some of the longest lived or more severe cases. We extracted consecutive files in proportion to their alphabetical distribution by surname. While surveying the archive, we found records of a few pensioners who had served in Victorian campaigns, notably Afghanistan, Egypt, and the Sudan. Twenty eight of these had functional somatic disorders, which fell into two broad diagnostic groups-cardiac (19), which included "palpitation" and "irritable heart," and debility (9).

\section{The first world war}

The only surviving war pension records from the first world war are held at the Public Record Office (PIN26). The 22756 pension records are drawn from the London Region of the Ministry of Pensions, which, under the decentralised system of May 1919, acquired responsibility for South East England. ${ }^{21}$ The sampling exercise was undertaken by War Pensions staff, who probably chose London region as the largest and most accessible holding. They selected every 50 th file to create a 2\% sample (22 756 files) from 1137800 records. An official report calculated that, by March 1930, 1644000 pensions or gratuities had been granted to veterans of the first world war, ${ }^{9}$ which suggests that the London region represented about $60 \%$ of the total number of pensions and gratuities awarded for the conflict.

We analysed the $2 \%$ sample by diagnosis and selected random samples of DAH (to provide a direct comparison with the Boer war) and shell shock, or neurasthenia as it was reclassified in 1917. We adjusted the proportions of officers to other ranks for DAH and neurasthenia to reflect their distribution within the total population (table 6 ).

\section{The second world war}

Pension files relating to the second world war and the Korean war are closed to public inspection and are held by the Department of Social Security. We obtained ministerial permission to gather anonymised data from these records. The structure of this large archive has important implications for the design of the sample, as specific periods of the war saw different groups of servicemen granted pensions. A detailed survey enabled files to be randomly selected in representative proportions (table 7). We chose three diagnostic groups-effort syndrome (for comparison with the Boer war and first world war samples of DAH), psychoneurosis (the terms neurasthenia and shell shock having fallen from use), and non-ulcer dyspepsia.

Table 6 Distribution of contemporary diagnosis for post-combat syndrome by rank in first world war servicemen. (Values are numbers (percentages) of cases)

\begin{tabular}{lccccc} 
& \multicolumn{2}{c}{ PIN 26 archive } & & \multicolumn{2}{c}{ Study sample } \\
\cline { 2 - 3 } \cline { 5 - 6 } Diagnosis & Other ranks & Officers & & Other ranks & Officers \\
\hline DAH & $1097(98.1)$ & $21(1.9)$ & & $196(98)$ & $4(2)$ \\
\hline Neurasthenia & $716(82.8)$ & $149(17.2)$ & & $166(83)$ & $34(17)$ \\
\hline
\end{tabular}

$\mathrm{DAH}=$ disordered action of the heart.
Table 7 Distribution of pensions for psychoneurosis in second world war

\begin{tabular}{lcc} 
Files (archive) & $\begin{array}{c}\text { Estimated total No } \\
\text { (\%) of pensions } \\
\text { (all diagnoses) }\end{array}$ & $\begin{array}{c}\text { No (\%) of cases } \\
\text { of psychoneurosis }\end{array}$ \\
\hline Regional (Nelson) & $133500(12)$ & $24(12)$ \\
\hline Central (Nelson and Heywood) & $750000(68)$ & $124(62)$ \\
\hline NINO* (Heywood) & $215000(20)$ & $40(20)$ \\
\hline Officers & Not known & $12(6)$ \\
\hline
\end{tabular}

*Organised by National Insurance number (NINO)

The second world war witnessed an epidemic of suspected duodenal ulcers. Dyspepsia was the largest single cause of medical invalidity from the British Expeditionary Force in France during 1939-40. ${ }^{22}$ Indeed, the incidence of peptic ulcer had risen steadily from 1900 and peaked in the early 1950s. ${ }^{10}{ }^{23}$ The focus of health concerns in Britain switched from the heart in the first world war to the stomach in the second world war. To assemble a sample of patients with dyspepsia, we had to extract a large number of veterans with a war pension for duodenal ulcer as few awards had been made for dyspepsia alone. Closer inspection revealed that a substantial number had undergone repeated barium meal radiography, with negative or conflicting findings. Cases with consistently negative radiological results were included in the study, and those with conflicting evidence were re-examined by a consultant radiologist for the purpose of this study. By allowing radiologists and gastroenterologists to inspect the duodenum in detail, modern endoscopy has also improved their ability to interpret radiographs. It was concluded with reasonable certainty that in about a third of suspected duodenal ulcer cases no crater had been present, and we added these to the sample. With this cautious approach, we collected a sample of 100 pensioners.

1 Unwin C, Blatchley N, Coker W, Ferry S, Hotopf M, Hull L, et al. Health of UK servicemen who served in Persian Gulf war. Lancet 1999;353:16978 .

2 Ismail K, Everitt BS, Blatchley N, Hull L, Unwin C, David A, et al. Is there a Gulf war syndrome? Lancet 1999;353:179-89.

3 Doebbeling BN, Clarke WR, Watson D, Torner JC, Woolson RF, Voelker $\mathrm{MD}$, et al. Is there a Gulf war syndrome? Evidence from a large population-based survey of veterans and nondeployed controls. Am J Med population-based surv

4 Haley RW, Thomas KL, Hom J. Is there a Gulf war syndrome? Searching for syndromes by factor analysis of symptoms. JAMA 1997;277:215-22, 278:388.

5 Hyams KC, Wignall FS, Roswell R. War syndromes and their evaluation: from the U.S. civil war to the Persian Gulf war. Ann Intern Med 1996;125:398-405

6 Jones E, Wessely S. The origins of British military psychiatry before the first world war. War Soc 2001;19:91-108.

7 Grinker RR, Spiegel JP. Men under stress, London: J and A Churchill, 1945:108.

8 Everitt BS, Landau S, Leese M. Cluster analysis. London: Edward Arnold, 2001.

9 Tibshirani R, Walther G, Hastie T. Estimating the number of clusters in a data set via the gap statistic. JR Soc Stat 2001;63:411-23.

10 Young A. The harmony of illusions: inventing post-traumatic stress disorder. Princeton, NJ: Princeton University Press, 1995.

11 Shephard B. A war of nerves, soldiers and psychiatrists 1914-1994. London: Jonathan Cape, 2000:1-3.

12 Feudtner C. 'Minds the dead have ravished': shell shock, history, and the ecology of disease-systems. Hist Sci 1993;31:377-420.

13 Grant RT. Observations on the after-histories of men suffering from the effort syndrome. Heart 1925;12:121-42.

14 Kang HK, Bullman TA. Mortality among US veterans of the Persian gulf war: 7-year follow up. Am J Epidemiol 2001;154:406-9.

15 Mitchell TJ, Smith GM. History of the great war based on official documents, medical services. London: HMSO, 1931:103, 315.

16 Langman MJS. The epidemiology of chronic digestive disease. London: Edward Arnold, 1979.

17 Tidy HL. Discussion on dyspepsia in the forces. Proc $R$ Soc Med 1941;34:21-36. 
18 Bergman BP, Miller SAStJ. Unfit for further service: trends in medical discharge from the British army 1861-1998. J R Army Med Corps 2000;146:204-11.

19 Shorter E. Paralysis - the rise and fall of a hysterical symptom.J Soc Hist 1986; $19: 549-82$

20 Shorter E. From paralysis to fatigue, a history of psychosomatic illness in the modern era. New York: Free Press, 1992.
21 Rhind TD. Decentralisation. War Pensions Gazette 1919:25:307-10

22 Green FHK, Covell G. Medical history of the second world war, medical research. London: HMSO, 1953.

23 Riley ID. Perforated peptic ulcer in war-time. Lancet 1942;2:485.

(Accepted 3 January 2002) 